\title{
Modelling and role-modelling: integrating nursing theory into practice
}

\author{
Kathleen Kelley Walsh MS RN \\ Director of Nursing (Resource Development), St Joseph's Hospital, Flint, Michigan
}

Terry M. VandenBosch MS RN CS

Nurse Specialist in Research, Catherine McAuley Health Center, and Adjunct Assistant

Professor, The University of Michigan School of Nursing

and Susan Boehm PhD RN FAAN

Associate Professor of Nursing, The University of Michigan School of Nursing, Ann Arbor, Michigan, USA

WALSH KELLEY K., VANDENBOSCH T.M. \& BOEHM S. (1989) Journal of Advanced Nursing 14, 755-761

Modelling and role-modelling: integrating nursing theory into practice This article contrasts two clinical cases using a relatively new paradigm and theory, modelling and role-modelling. The concepts and linkages from modelling and role-modelling are presented and are the basis for analysing the outcomes of two patients. The case study approach communicates an understanding of the theory modelling and role-modelling and assists nurses to develop expertise in its use.

\section{INTRODUCTION}

Nursing is a profession which is simultaneously art and science. What makes our job of enhancing people's health both continually exciting and sometimes elusively frustrating is this fusion of art and science. If our goal is to assist each client in their growth as people, we need to cultivate both our scientific foundations for action and our artful performance of them. We can heighten our ability to practise both the art and science of nursing if our work is grounded in theory. The raw materials a nursing theorist works with are the concepts which our profession is concerned with: people, nursing, health and environment. These concepts are linked together and the resulting relationships are analysed and made explicit. Pre-existing facts and ideas are combined to look at the world in a new way. How a theory illustrates the world can then be tested to see how well it fits with reality.

One fairly new theory has drawn together previously developed knowledge and added new ideas and ways of looking at nursing. It describes the scientific bases useful for our profession and our unique contribution to clients via the art and science of nursing practice. The theory, called modelling and role-modelling, was developed by Helen Erickson, Mary Ann Swain, and Evelyn Tomlin (Erickson et al. 1983). It is a complex theory because of the integration of several theories and ways of looking at man. Although the theory contains many levels of meaning, its basic concepts make sense, and can be readily applied to nursing practice. This article presents some of the concepts and linkages of modelling and role-modelling through case studies of two individuals.

\section{CASE NUMBER 1}

Jim is a young man in his late twenties who has the congenital bleeding disorder of haemophilia A (factor VIII deficiency). Like most severe haemophiliacs he has suffered from numerous spontaneous and trauma-induced episodes of bleeding into his joints and muscles. The repeated internal bleeds have eroded the lining of several of his 


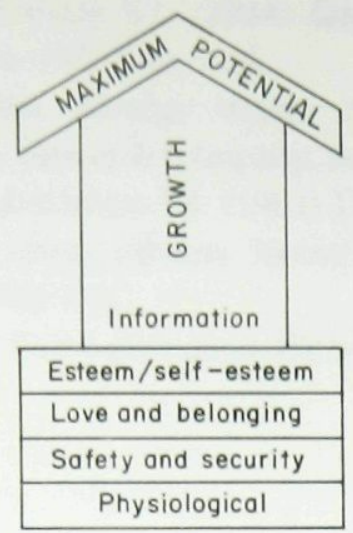

Figure 1 Maslow's hierarchy of needs.

joints, resulting in arthritis and reduced mobility. The influence of haemophilia extends beyond the physical realm. Modelling and role-modelling (M \& RM) states people are holistic. Jim's haemophilia, therefore, was experienced by and caused effects on his total being. Using $M$ \& RM to explore these effects can give us insight into Jim's world. The theory emphasizes the importance of human development, and adds new links to pre-existing theories. This case study will illustrate some of the concepts and linkages explained in $M$ \& RM.

The theories of Abraham Maslow $(1968,1970)$ and Eric Erikson (Erickson 1963) are important building blocks for M \& RM. Diagrams of these levels and stages are included in Figures 1 and 2. M \& RM links Maslow's theory of human needs with Erickson's theory of human development. The degree to which developmental tasks are resolved is dependent on the degree to which human needs are satisfied (Erickson et al. 1983). Integrating the conceptual frameworks of Maslow and Erickson facilitates our understanding of how people grow to be both alike and different.

For example, Erickson (1963) identified the initial conflict every infant faces as they enter a strange new world as trust versus mistrust. Like other infants Jim took in nourishment when hungry, and thus learned his mother could be trusted to provide for his needs. In Erickson's terms he was building the strength of trust. Having his basic physical needs met was helping him to feel safe and secure according to Maslow's heirarchy. Synthesizing the two theories tells us that having basic needs fulfulled provides Jim with the security and sustenance to work on the developmental task at hand.

We might ask if the haemophilia had particular influences on Jim's infancy. Like many haemophiliacs, Jim was free of bleeding into joints and muscles for the first several months of his life. Physically he was unaffected for almost a year, except for excessive bleeding during circumcision. This episode led to testing which substantiated the diagnosis of haemophilia. His mother was then informed she carried the genetic trait which her son had inherited as haemophilia. This information impacted her basic need fulfilment, and therefore her ability to cope. She reacted with grief, guilt, and a determination to fight the haemophilia and protect her son. Jim's physiologic needs were well attended to during infancy and throughout his life. Nevertheless, his mother's inability to cope adaptively with her feelings about having a son with haemophilia profoundly affected Jim, beginning in infancy. Unresolved morbid grief over transmitting the haemophilia impacted her ability to nurture Jim's development of strengths.

Within a few months babies develop the physical mobility to actively explore the environment, and simultaneously begin learning that they are a separate individual. Like all babies, as Jim began to realize he was separate from mother he would move away from her for a few minutes, returning periodically for her assurance. $M$ \& RM labels the need to be both autonomous and dependent 'affiliatedindividuation'. This concept describes the importance and coexistence of both the 'I' and 'we' states of being. That is, all people need to experience freedom and acceptance in both states, being separate and being linked to others. This connection to others is our affiliation or attachment. A second theoretical linkage of $M$ \& RM is between this attachment to an object (a person, or in some cases an idea or thing) and basic need satisfaction. The degree to which needs are met by attachment depends on the availability of the object (i.e. mother) and the amount of comfort and security as opposed to threat and anxiety which it provides. Thus, object-loss results in basic need deficits. Life entails ongoing losses, some of which are never completely resolved. The more important the object to basic need fulfilment the more likely that its loss will cause unresolved morbid grieving.

With these concepts in mind let us return to examining the stages of human development.

Erickson's second stage involves a conflict which impacts an individual's sense of affiliated-individuation. Recall that affiliated-individuation is an intrapsychic phenomena in which the person perceives they are simultaneously close to and yet separate from significant others. The person perceives freedom and acceptance whether dependant on or autonomous of the significant other. At Erickson's second developmental level, the child is grappling with autonomy versus doubt. The conflict involves recognizing self as separate from mother by exercising independence versus parental attempts to control or channel behaviour in socially accepted ways. One important activity of this stage of development is toilet training. The child learns they have control over their body wastes, and 
Figure 2 Erikson's developmental stages.

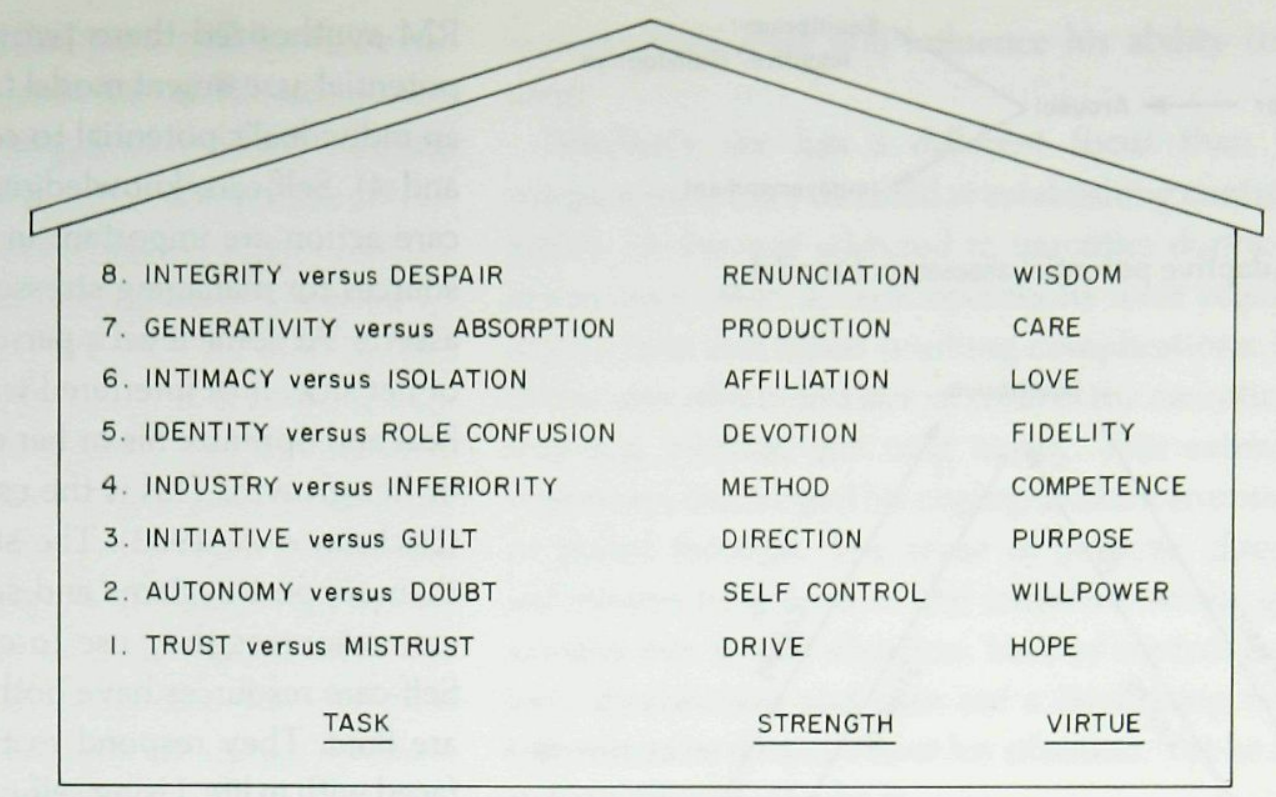

also learns how to use this control to elicit various reactions from parents.

Where does Jim fit in here? By the time he was about 10 months old the activities of crawling and walking were resulting in painful episodes of bleeding into joints and muscles. Attempts at exploring the world were somehow connected with pain for reasons he could not understand. The episodes were irregularly spaced. Sometimes days elapsed between bleeds, at best 2 to 3 weeks free of bleeds passed. His concerned mother tried curbing his actions, hoping to prevent bleeds. Unfortunately, people with haemophilia often bleed spontaneously into joints, and injury is not necessarily a prerequisite. Swollen, restricted joints are acutely painful, and the comfort of his mother could not completely relieve the hurting.

Twenty years ago, before the introduction of factor concentrates, home care and speedy outpatient care, persons with haemophilia experienced frequent hospitalizations. Therefore, when bleeds occurred Jim was separated from his family. Jim's developing sense of affiliated individuation was negatively impacted by the frequent separations, and his mother's attempts to protect him from harm which became quite restrictive. The pain and immobility he could not understand eroded the earlier achievement of feeling safe, secure and trusting. In addition to impacts on Erickson's eight stages of development and Jim's sense of affiliation was the impact on Jim's basic needs according to Maslow. Jim's basic needs were frequently threatened. A strong foundation of basic need satisfaction provides the basis for human development. Without it healthy growth is inhibited by morbid grieving.

The bleeds continued as Jim moved into toddlerhood with autonomy versus doubt conflict and control issues.
When his actions resulted in pain for no apparent reason, his developing sense of control was negatively impacted. He built up more shame, fears and doubts than most children, because his fledgling attempts to gain autonomy were frequently thwarted by his worried mother or by a bleeding joint. The unpredictable bleeding episodes meant Jim never felt much control over his environment, and even over himself. Doubtful feelings built up, hampering his ability to experience independence.

For all people the outcomes of each stage contain varying degrees of positive development and negative residual development. It is expected to have some negative residual development. However, more negative residual than positive residual hampers the development of enduring strengths and virtues that contribute to the character and health of an individual (see Figure 2). For Jim, the strength of self-control and hope he developed were considerably lessened by the lack of control he experienced. Regardless of the degree to which we positively resolve a developmental task, advancing age thrusts the next stage upon us. The degree to which we have resolved a stage, and the strengths and fears which result, are carried over, affecting our experience with the next stage.

Jim brings self-doubt to the next childhood task — that of initiative versus guilt. He finds that his actions sometimes coincide with a bleed. He feels guilty about his bleeds and assumes he is being punished. In attempting to protect their son from bleeds his parents stifle Jim's attempts to take initiative in activities. The overprotectiveness diminishes self-learning which normally occurs through play. Instead of developing a sense of direction and purpose in himself, he feels guilty which further inhibits his growth. Jim as an adult rarely initiates new activities or 


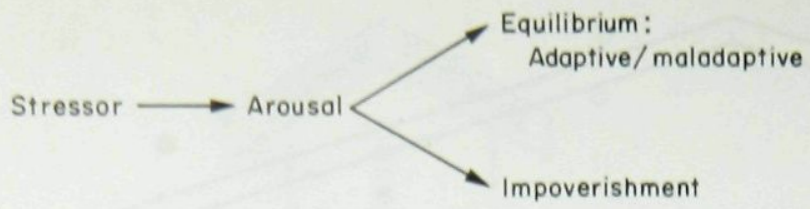

Figure 3 Adaptive potential assessment model.

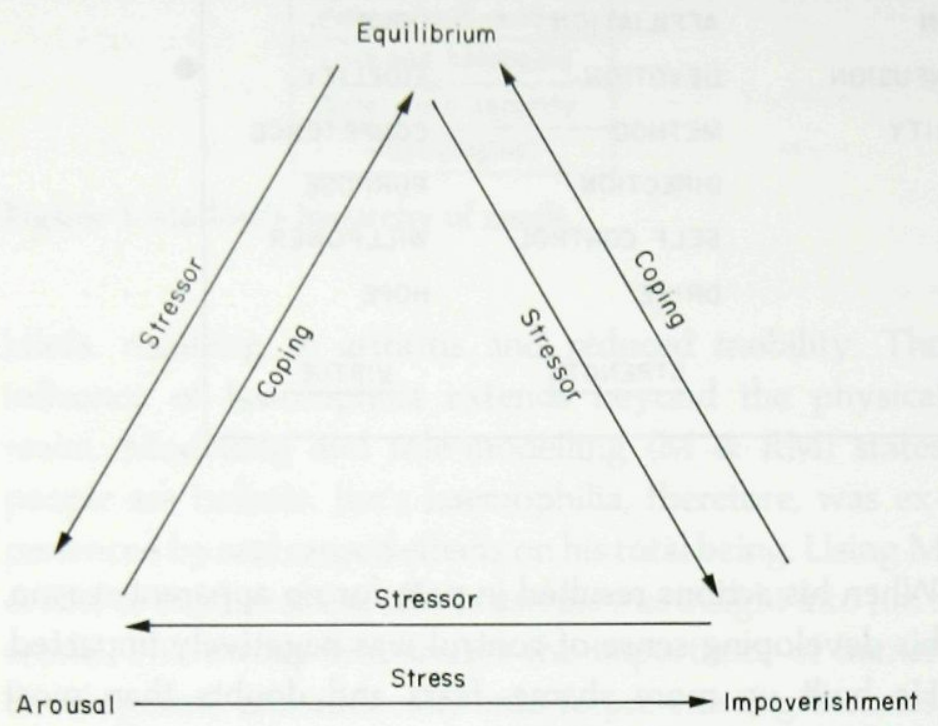

Figure 4 An illustration of the dynamic relationship among the states of the adaptive potential assessment model.

relationships with others. Without correcting this fundamental need to feel in control, Jim's potential for healthy growth is stunted.

Once again, the doubt and guilt are carried over when Jim reaches the next developmental level. His poor resolution of the previous task results in a higher residual of negative effects, and a lower residual of positive effects for that developmental task. According to Erickson, the basic strength that emerges from autonomy versus shame and doubt is self-control. Although Jim did not completely resolve this task, he did develop some strengths. Humour was a strength he developed which gives him control in some situations. One way Jim reveals his feelings and his sense of himself is through his use of a wry form of humour. On the other hand, the type of humour he chooses often reflects his low self-esteem and an inability to express feelings. Space limitations prohibit our walking through each of Erikson's stages and Maslow's levels in this article. Examine the chart and think for youself about how Jim is equipped to deal with the remaining developmental stages.

Human beings are complex. Identifying enduring characteristics from development and basic need satisfaction provides some information in understanding human behaviour. Another model used in M \& RM draws from Selye's (1974) general adaptation syndrome and Engel's (1962) responses to stressors theories. The authors of M \&
RM synthesized these two and developed the adaptive potential assessment model (APAM) to assist in predicting an individual's potential to cope with stress (see Figures 3 and 4). Self-care knowledge, self-care resources and selfcare action are important in the potential to mobilize resources for managing stressors (Erickson 1984). M \& RM asserts 'At some level a person knows what has made him or her sick... or interfered with growth and what will help heal and optimize his or her effectiveness and promote his or her growth. This is the essence of self-care knowledge (Erickson et al. 1983). The strengths people develop and their support systems and social networks form the selfcare resources they use to cope with the stresses of life. Self-care resources have both enduring characteristics and are fluid. They respond to the continual changes we are faced with in life. Using self-care knowledge and our ability to mobilize our resources is our self-care action. The third linkage in M \& RM states, 'An individual's potential for mobilizing resources - the person's state of coping according to APAM - is directly associated with the person's need satisfaction level' (Erickson et al. 1983). Numerous basic need deficits limit potential for mobilizing self-care resources. The APAM model depicts three categories or states. Each state represents a different potential for mobilizing resources at that point in time: arousal, equilibrium (adaptive or maladaptive), and impoverishment. Physiologic and psychologic data have been gathered to substantiate the three main states of adaption potential the model proposes (Erickson \& Swain 1982). Assisting people in replenishing, developing and using their resources for movement in a healthier direction is a prime nursing responsibility.

The APAM is used when assessing an individual's potential for coping at a particular moment in time. It indicates their state. Currently Jim is in an impoverished state according to APAM. His coping abilities and strengths are limited by his basic need deficit. Two years ago he sustained serious injuries in an automobile accident and became even more withdrawn. The level of depression was such that some basic self-care activities were not performed. The change in his ability to cope is described in terms of the APAM model as a move from maladaptive equilibrium to impoverishment. Since the APAM reflects the current coping state, it must be continually reassessed. Jim has been moving back and forth between maladaptive equilibrium and impoverishment during the past 2 years.

\section{CASE NUMBER TWO}

Michael is in his late twenties and also has severe haemophilia A. He experienced events in his infancy and early 
childhood which closely paralleled Jim's. Like Jim he developed trust and had his basic needs for safety and security met as an infant. Similarly, as he gained mobility, bleeding episodes began impacting his life. The completely unpredictable occurrence of joint haemorrhages which suddenly interrupted activities, plans and comfort robbed Michael of feeling in control of himself. To this point Jim and Michael had similar experiences. The difference was with the developmental task of initiative versus guilt. Michael's parents promoted safety but also gave him the freedom to take risks. He was allowed to try things out, test himself, and learn from his actions. For example, he learned to operate farm equipment, and was allowed to run and play with the neighbourhood children. Michael still has difficulty with control issues, however his strength of taking initiative without oppressive guilt is a resource.

The internal strengths Michael developed, coupled with a supportive family, suggest his adaption potential is different from Jim's. He continues to have positive expectations and goals for his future. Using the APAM model we see he is in equilibrium. When stressors arouse him he mobilizes his resources and uses them effectively. In contrast, when Jim faces significant stress he lacks the strengths to maintain equilibrium and instead sinks further into impoverishment.

\section{PRESENT SITUATION FOR MICHAEL AND JIM}

Given these similarities and differences what is each man's life like today? The situations of each are not surprising. Both continue to struggle with control issues as they face the stages of life presented to them. But their struggles are different from one another.

Jim never left home, found employment, or developed intimate relationships with anyone other than his immediate family. The adolescent conflict of identity versus role diffusion is one Jim has not yet resolved. In fact, he seems to lack the energy necessary to deal with the issue of who he is. His self-esteem is very low and he is depressed. His interests, when he addresses them, are solitary pursuits. Occasionally he paints (objects not people), and he displays affection towards his cat. He stays in his room, communicating with others only when necessary. Presently he is incapable of choosing intimacy over isolation. His health has steadily deteriorated over the past few years. Like most severe haemophiliacs he has been exposed to the causative agent in AIDS, the HIV virus. Jim is beginning to have signs and symptoms that the virus is altering his immune system. Although not yet diagnosed with AIDS, his impoverished state will influence his ability to fight the virus.

Michael's life has a different focus than Jim's. His energies have been directed at establishing control through action. He became addicted to narcotics during a time of severe pain when several operations were required to replace a joint and repair resulting complications. Disgusted by the side effects and lack of control the narcotic addiction imposed, Michael quit cold turkey. This extremely hard experience challenged his coping abilities enormously, and he pulled through. The sense of purpose, direction, and self-esteem he gained in the initiative versus guilt stage assisted him in this situation. Lack of control over severe joint dysfunction and pain are a continuing reality, and sometimes he despairs over his situation. Yet he retains his strong sense of who he is.

Currently Michael is completing his PhD. He finds focusing his attention on intellectual pursuits helps decrease the perception of pain from his arthritic joints. Michael struggles with the issue of how close to allow other persons. He openly describes his hesitancy to become involved with a woman because of his uncertain future. Prior to 2 years ago he had girlfriends, but since that time his concern over not exposing anyone to AIDS via sexual contact has resulted in a decision not to become involved with women in an intimate way. So developmentally we see he is struggling with the stage of intimacy versus isolation. Although he knows of his exposure to HIV, presently Michael shows no signs of immune system impairment.

\section{MODELLING AND ROLE-MODELLING AND THE NURSING PROCESS}

The central concept of $M$ \& RM states the nurse must understand a client's world. The nurse models his world as it exists for him. Modelling contains both the art and science of nursing. It combines scientific aggregation and analysis of data with the image and understanding of the world from the client's view. When one sees the world as the client does, then one can role-model. 'Role-modelling is the facilitation of the individual in attaining, maintaining, or promoting health through purposeful interventions' (Erickson et al. 1983). Role-modelling is science because it draws on the theoretical bases of nursing practice. It is art because the nurse plans and intervenes within the person's own unique model. The bedrock of the nurse's action is unconditional acceptance, positive regard, facilitation, and nurturance of the individual. These attitudes permeate the nurse's approach if the relationship is successful. 
The nursing process as visualized by $M$ \& RM is defined by the relationship to the client. The nurse brings his or her whole self into an intensive, interpersonal relationship with the client. The nursing process which results is continual and therapeutic, as opposed to a rigid sequence of steps. From the first moment of contact a nurse is intervening, simply by listening and analysing data. She evaluates what she is perceiving in this give-and-take dialogue and responds further. This dynamic process continues throughout the relationship. The more formal aspect of the nursing process is reflected in the theory and knowledge base she uses in her actions, her analysis and responses in the nurse-client relationship, and her documentation of what is occurring.

One important implication of this theory is focusing on the client's perception. The client's concerns preempt the nurse-identified concerns. If the need most central to the individual is addressed, we know their holistic response will also impact needs the nurse has identified, which the client may not have been aware of or focused on. Establishing trust and then positively impacting a client is only possible if what is important to that individual receives attention.

To model the client's world the nurse gathers key information from the client and appropriate significant others. Areas the nurse addresses include how the individual views their situation, their current and future expectations, their strengths and support systems, and finally their goals (Campbell et al. 1985). As the interpersonal relationship continues to develop, the client will share those issues important for them. The art of nursing is listening and discovering those issues. The science of nursing is being able to understand those issues within the framework of the theory.

\section{Using information}

The next question one might ask is: how does the nurse use the information as she relates to the client? The authors of M \& RM suggest five aims of nursing interventions which reflect the theoretical bases and the linkages. The five aims and their principles are presented in Table 1.

Incorporating these principles into nursing practice enables one to more readily perceive where the client is, and promote their healthy adaptation and role-model growth. Maslow discussed the inability of humans to grow unless the threatening aspects of growth can be minimized and the appeal for growth is maximized, while the person's need to be safe is met. When people feel safe, secure and supported they will choose health. A basic belief of M \& $\mathrm{RM}$ is that people are born with an inherent desire to grow and fulfill their self-potential. That is what nursing is all about. We work with people by nurturing their humanity, helping them to help themselves.
Interventions which reflect the client's world and promote growth are not necessarily difficult to decide upon and act out. In fact they are often simple. For example, in communicating unconditional positive regard and nurturance, touch can be very useful. Of course, it must occur within the context of the model of the client's world. For Jim, who keeps people at arms length, the nurse gradually progressed in the use of touch. Initially she began with the clinically necessary act of gently palpating an extremity with an internal joint bleed, to playfully tweaking his big toe as a standard greeting when entering or leaving his hospital room (allows for his sense of personal space, not as threatening as touching more centrally, such as his face), to sitting on his bed to converse, to squeezing his hands. For each client and each nurse the use of touch will be personalized. This is the art of nursing.

\section{Basic needs}

In designing interventions identify the person's basic needs according to Maslow, and build on existing strengths. Whereas Jim has difficulty stating his needs, Michael is able to identify what will help him. Michael's knowledge about haemophilia and its treatment is high. Like the majority of adults with severe haemophilia, he is on a programme called home care. This means he has been taught to analyse his bleeds, calculate dosages, reconstitute and administer factor VIII concentrate, perform venipuncture on himself, and keep a log of these episodes. Essentially he is in control of his treatment. The haemophilia centre team is available to help in acute situations, examine his logs; and evaluate his health and development periodically to plan for the future.

When Michael enters the hospital he relinquishes much of the control over his care he enjoys at home. Since maintaining control is important for Michael, an important intervention is to return control to him to the extent possible. An example of returning control and building on his strengths is to acknowledge Michael's expertise and facilitate the continuation of his self-care activity in the hospital. Michael was allowed to perform his own venipunctures and administer his factor concentrates during his last hospital admission. He felt less threatened, more in control, and took positive steps towards discharge when these measures verifying ownership of his health and self were instituted.

\section{A base for practice}

All nurses have experienced the wonders of relating to a client in a way which successfully enhances the client's ability to cope and grow. Conversely, we have endured 
Table 1 Relationships among intervention goals, principles, and aims for intervention

Intervention goal lationship between yourself and you client

2. Facilitate a self-projection that is futuristic and positive

3. Promote affiliated individuation with the minimum degree of ambivalence possible

4. Promote a dynamic, adaptive, and holistic state of health

5. (a) Promote (and nurture) coping mechanisms that satisfy basic needs and permit growth-need satisfaction

(b) Facilitate congruent actual and chronological developmental stages
Principle

The nursing process requires that a trusting and functional relationship exists between nurse and client

Aim

Build trust

Promote client's positive orientation the individual's perceiving that he or she is an acceptable, respectable, and worthwhile human being

Human development is dependent on the individual's perceiving that he or she has some control over life (while concurrently sensing a state of affiliation)

There is an innate drive toward holistic health that is facilitated by consistent and systematic nurturance

Human growth is dependent on satisfaction of basic needs and is facilitated by growth-need satisfaction
Affirm and promote client's strengths

Set mutual goals that are healthdirected frustrating situations where our efforts did little to effect a positive outcome. $M$ \& RM provides the theoretical foundation to understand these experiences. It also provides a scientific base to propel our nursing practice.

\section{Acknowledgement}

Figures 1, 2, 3, 4 and Table 1 are reprinted with permission from Erikson, Tomlin and Swain Modeling and RoleModeling: A Theory and Paradigm for Nursing. Prentice-Hall Inc., Englewood Cliffs, New Jersey, 1983.

\section{References}

Campbell J., Finch D., Allport C., Erickson H.C. \& Swain M.A. (1985) A theoretical approach to nursing assessment. Journal of Advanced Nursing 10, 111-115.
Engel G.S. (1962) Psychological Development in Health and Disease. Saunders, Philadelphia.

Erikson E. (1963) Childhood and Society. W.W. Norton, New York. Erickson H.C. (1984) Self-care knowledge: relations among the concepts support, hope, control satisfaction with daily life and Physical Health Status. Unpublished doctoral thesis, University of Michigan.

Erickson H.C., Tomlin E.M. \& Swain M.A.P. (1983) Modeling and Role-Modeling: A Theory and Paradigm for Nursing. PrenticeHall, Englewood Cliffs, New Jersey.

Erickson H. \& Swain M.A. (1982) A model for assessing potential adaptation to stress. Research in Nursing and Health 5, 93-101.

Maslow A.H. (1968) Toward a Psychology of Being, 2nd edn. D. Van Nostrand, New York.

Maslow A.H. (1970) Motivation and Personality, 2nd edn. Harper \& Row, New York.

Selye H. (1974) Stress Without Distress. Lippincott, Philadelphia. 
This document is a scanned copy of a printed document. No warranty is given about the accuracy of the copy. Users should refer to the original published version of the material. 